\title{
The flow pattern north of Taiwan and the migration of the Kuroshio
}

\author{
T.Y. Tang*, J.H. Tai, Y.J. Yang
}

Institute of Oceanography, National Taiwan University, Taipei, Taiwan, ROC

\begin{abstract}
The migration of the Kuroshio and mesoscale flow pattern north of Taiwan were studied using the historical ship-board acoustic Doppler current profiler (Sb-ADCP) current velocity and hydrographic measurements, moored current velocity, water temperature and salinity time series, snapshot current velocity observations and infrared images. The Kuroshio migrated both seasonally and intra-seasonally, with the former being more pronounced. The flow pattern north of Taiwan was significantly impacted by the seasonal migration of the Kuroshio. In summer the Kuroshio generally moved away from the shelf, colliding with the zonally running shelf breaks of the East China Sea (ECS) and splitting into an eastward mainstream and a northwestward branch current. Southwest of the branch current, a counterclockwise circulation was found along the edge of the shelf northeast of Taiwan, through which the subsurface Kuroshio water intruded forming a cold dome. In winter the Kuroshio moved close to and sometimes onto the northern shelf of Taiwan. The intrusion of the Kuroshio dominated the flow pattern in the region, causing the disappearance or obscuration of the counterclockwise circulation and cold dome. A sharp horizontal temperature front accompanying the horizontal velocity front was found on the northern shelf of Taiwan, through which the current flowed mainly northward against the winter monsoon. Intra-seasonal variations in flow patterns north of Taiwan and the intra-seasonal migration of the Kuroshio were also studied. In summer the counterclockwise circulation and cold dome migrated shoreward/seaward with the intraseasonal migration of the Kuroshio. In winter the Kuroshio either intruded onto the shelf just off the northern tip of Taiwan or slightly further north. The resulting flow patterns north of Taiwan varied with the path of the intruding Kuroshio. Though the impact of the Taiwan Strait outflow on the flow pattern north of Taiwan was not negligible, it was not as great as the impact of the Kuroshio. Conversely, the intrusion of the Kuroshio strongly influenced the Taiwan Strait outflow. In summer counterclockwise circulation blocked the Taiwan Strait outflow and
\end{abstract}

\footnotetext{
* Corresponding author.
} 
directly interacted with the Kuroshio. In winter the outflow joined with the on-shelf Kuroshio north of Taiwan. C 2000 Elsevier Science Ltd. All rights reserved.

Keywords: Kuroshio migration; Mesoscale flow pattern; East China Sea

\section{Introduction}

The northern shelf of Taiwan is an extremely dynamic oceanic region. The Kuroshio flows along its eastern side, frequently intruding onto the shelf itself. A cold dome of subsurface Kuroshio water (Chern and Wang, 1989) was observed at the edge of the shelf (Uda and Kishi, 1974; Fan, 1980; Liu et al., 1992). On its western side, the water generally flows out from the Taiwan Strait (Wang and Chern, 1988) and interacts with the intruding Kuroshio. This suggests a rather complicated flow pattern.

The construction of the mesoscale flow pattern northeast of Taiwan, generated by the collision of the Kuroshio with a section of the continental shelf that runs nearly east-west, was obtained from a snapshot observation using a ship-board acoustic Doppler current profiler (Sb-ADCP) (Tang et al., 1999). Taken on August 10-17, 1994, the measurements of this flow pattern at 16, 104, and $200 \mathrm{~m}$ can be found in Fig. 1. The arrows indicate the current velocity while the thin lines represent the contours (200-1000 $\mathrm{m}$ at $200 \mathrm{~m}$ intervals) of bottom topography. It can be seen that the northeastward Kuroshio was blocked by the steep, zonally running break of the East China Sea (ECS) and then separated into two parts: the mainstream and its branch. The mainstream turned eastward along the break. The branch current flowed to the northwest, carrying the saline and warm Kuroshio water onto the shelf of the southern ECS through the North Mien Hwa Canyon (NMHC). A counterclockwise circulation of about $100 \mathrm{~km}$ in diameter was observed southwest of the branch current, centered around the Mien Hwa Canyon (MHC) and coinciding with the observed cold dome. The subsurface Kuroshio water intruded onto the northern shelf of Taiwan via this circulation, flowing out of the shelf region off the northern tip of Taiwan. The southwestward countercurrent found around MHC (Chuang et al., 1993) is a part of this circulation. Although the snapshot observation appears to capture the key features of the mesoscale flow pattern, such important issues as temporal variability are left unaddressed.

Long-term geomagnetic electrokinetograph (GEK) measurements reveal a seasonal migration of the Kuroshio main axis northeast of Taiwan (Sun, 1987). The Kuroshio appeared to shift shoreward in fall and winter, and seaward in spring and summer. Current meter observations made around the MHC showed on-shelf intrusion to occur about one month after the intensification of the winter monsoon, indicating shoreward displacement of the Kuroshio (Tang and Yang, 1993). Accompanying this intrusion was the disappearance of the southwestward countercurrent in the upper ocean $(<150 \mathrm{~m})$, subsequently replaced by the northwestward (shelfward) current. Using an infrared image taken in winter, Qiu and Imasato (1990) also observed the 

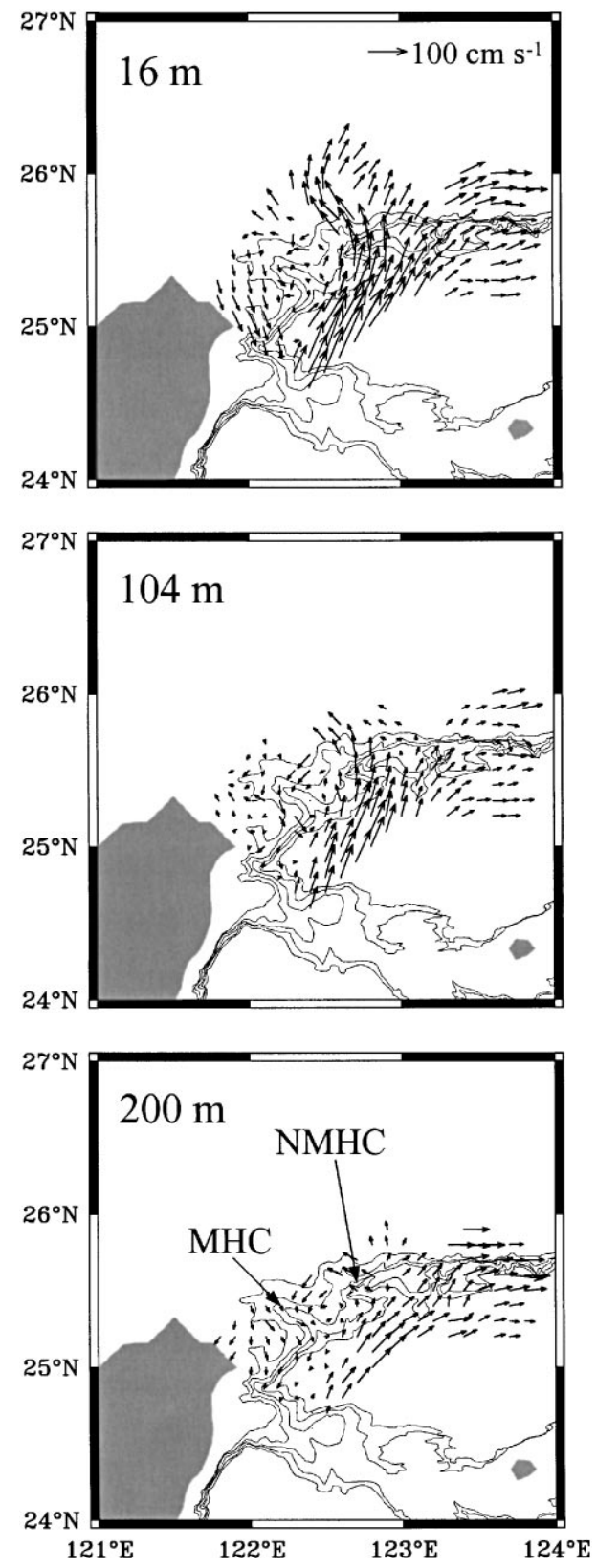

Fig. 1. Current velocity vectors from Sb-ADCP observations at (a) $16 \mathrm{~m}$, (b) $104 \mathrm{~m}$, and (c) $200 \mathrm{~m}$ depths. Thin lines indicate bathymetric contours (200-1000 m deep) at $200 \mathrm{~m}$ intervals (adapted from Tang et al., 1999). 
direct intrusion of the Kuroshio onto the northern shelf of Taiwan. This intrusion ceased as the winter monsoon collapsed around April (Chuang and Liang, 1994). No doubt the annual variation of flow pattern northeast of Taiwan can be significantly impacted by the seasonal migration of the Kuroshio.

Another important issue relevant to the mesoscale flow pattern described by Tang et al. (1999) is the impact of the Taiwan Strait outflow. Current meter observations in the central and southern Taiwan Strait (Wang and Chern, 1988; Chuang, 1986) reveal the flow to be generally northward. A southward current was found only when the northeasterly monsoon intensified and maintained its strength for several days. Yet no study has been made to investigate how the Taiwan Strait outflow interacts with the intrusion of the Kuroshio water onto the northern shelf of Taiwan.

The objective of this paper is to study the seasonal variation of mesoscale flow patterns north of Taiwan and their relation to the migration of the Kuroshio. Since historical moored current meter observations indicated the occurrence of seasonal transitions around April and October, "summer" will hereafter refer to the period between May and October, and "winter" to that between November and April. The migration of the Kuroshio current will be described in terms of current velocity and hydrographic data recorded by a self-contained acoustic Doppler current profiler (ADCP) and SEACAT conductivity-temperature-depth (CTD). Three snapshot current velocity distributions (one in summer and two in winter) provided by the $\mathrm{Sb}-\mathrm{ADCP}$, and the mesoscale flow pattern given by Tang et al. (1999) will be used to study the current variations north of Taiwan. The interaction between the intruding Kuroshio and the Taiwan Strait outflow will be discussed, as well as the relationship between the migrations of the Kuroshio and variations of mesoscale flow patterns north of Taiwan.

\section{Data}

Vertical constructions of the Kuroshio current velocity were made before and after the disruption of the zonally running shelf break northeast of Taiwan, using composite Sb-ADCP current velocity (compiled in 1991-1997) and hydrography (compiled in 1985-1997). The data has been provided by the Ocean Data Bank/National Center for Ocean Research (ODB/NCOR) of the National Science Council. Current velocity was generally recorded every $1-2 \mathrm{~min}$ in a depth bin of 4-8 $\mathrm{m}$ wide and 16-320 m deep. Calibration of the Sb-ADCP (Tang and Ma, 1995) and the use of a 30 min convolution average resulted in a root mean square (rms) error of $3.5 \mathrm{~cm} \mathrm{~s}^{-1}$. Composition of results was effected through linear interpolation of the raw data and vertical profile resampling at fixed $10 \mathrm{~m}$ intervals. The data was then categorized into $0.25^{\circ} \times 0.25^{\circ}$ grids, within which all values three standard deviations from the mean were deleted. The averaged composite was finally applied to the grids, each consisting of more than 50 bits of data.

Composite current velocity and hydrography northeast of Taiwan, as well as temporal variability and the migration of the Kuroshio, using time series of current velocity, water temperature, and salinity, were obtained from a set of self-contained 
ADCP mooring. Moored west of NMHC from July 1992 to March 1994, deployment lasted a total of 18 months, with approximately three months of interruption. The mooring location and diagram are shown in Fig. 2. A $150 \mathrm{kHz}$ narrow band ADCP with $20^{\circ}$ transducer was mounted onto a $45^{\prime}$ syntactic foam buoy (800 lbs. buoyancy). A flasher, radio beacon, and AGROS transmitter were mounted onto the top buoy to aid in the retrieval of the mooring. A self-recording SEACAT CTD was placed $2.5 \mathrm{~m}$ beneath the buoy, and twin acoustic releases were mounted parallel to each other, a short distance from the bottom. Since the mooring was retrieved and redeployed twice, the location of the three deployments (July-December 1992, March-August 1993, and August 1993-March 1994) changed slightly. The local water depth was around $580 \mathrm{~m}$. The mean depths of the ADCP for the three deployments varied from 270 to $200 \mathrm{~m}$, mainly due to miscalculations of the length of the required mooring wire. The mooring itself, however, was fairly consistent. The tilt of the buoy was generally less than $2^{\circ}$ and the vertical excursions (indicated by the CTD pressure sensor) were generally less than $5 \mathrm{~m}$, with a maximum value of $20 \mathrm{~m}$. The current velocity data was corrected for magnetic deviation and sound speed at the transducer and then linearly interpolated, with the vertical profile resampled at fixed $10 \mathrm{~m}$ intervals. The vector averaging current meter (VACM), mounted $150 \mathrm{~m}$ beneath the ADCP, was only used during the third deployment.

The seasonal mesoscale flow pattern north of Taiwan was obtained from four snapshot (including one of Tang et al., 1999) current velocity measurements taken by the Sb-ADCP. Three cruises were conducted to map the mesoscale spatial flow patterns. Fig. 3 shows the executed tracks of the three cruises (labeled A, B, and C), with the bathymetry of the survey area represented by depth contours $(200-1000 \mathrm{~m})$ at $200 \mathrm{~m}$ intervals. Cruises A, B, and C were conducted in the following periods, respectively: July 24 - August 5, 1996, March 16 - 18, 1995, and March 3 - 13, 1997. Due to difficult sea conditions, the proposed tracks were significantly altered. Along each cruise track, the current velocity was measured by the Sb-ADCP. All measurements were repeated twice, and the phase average method (similar to the method of Tang et al., 1999) was applied to reduce the effects of the $M_{2}$ tide. One research vessel was used in Cruise A and B, while two vessels were used in Cruise $\mathrm{C}$. The time intervals between the two measurements for Cruise A, B, and C were as follows: 43.47, 68.31, and $6.21 \mathrm{~h}$, which corresponds to $3.5,5.5$, and 0.5 times the $M_{2}$ tidal periods, respectively. The margin for error of the phase-averaging method was estimated (details seen in Tang et al., 1999), with the rms error for Cruise A, B, and C being 10, 11, and $6 \mathrm{~cm} \mathrm{~s}^{-1}$, respectively. Seasonal and intra-seasonal similarities and differences, the relationship between flow pattern variations and the migration of the Kuroshio, as well as the impact of the Taiwan Strait outflow on the mesoscale flow pattern north of Taiwan, were also noted. 

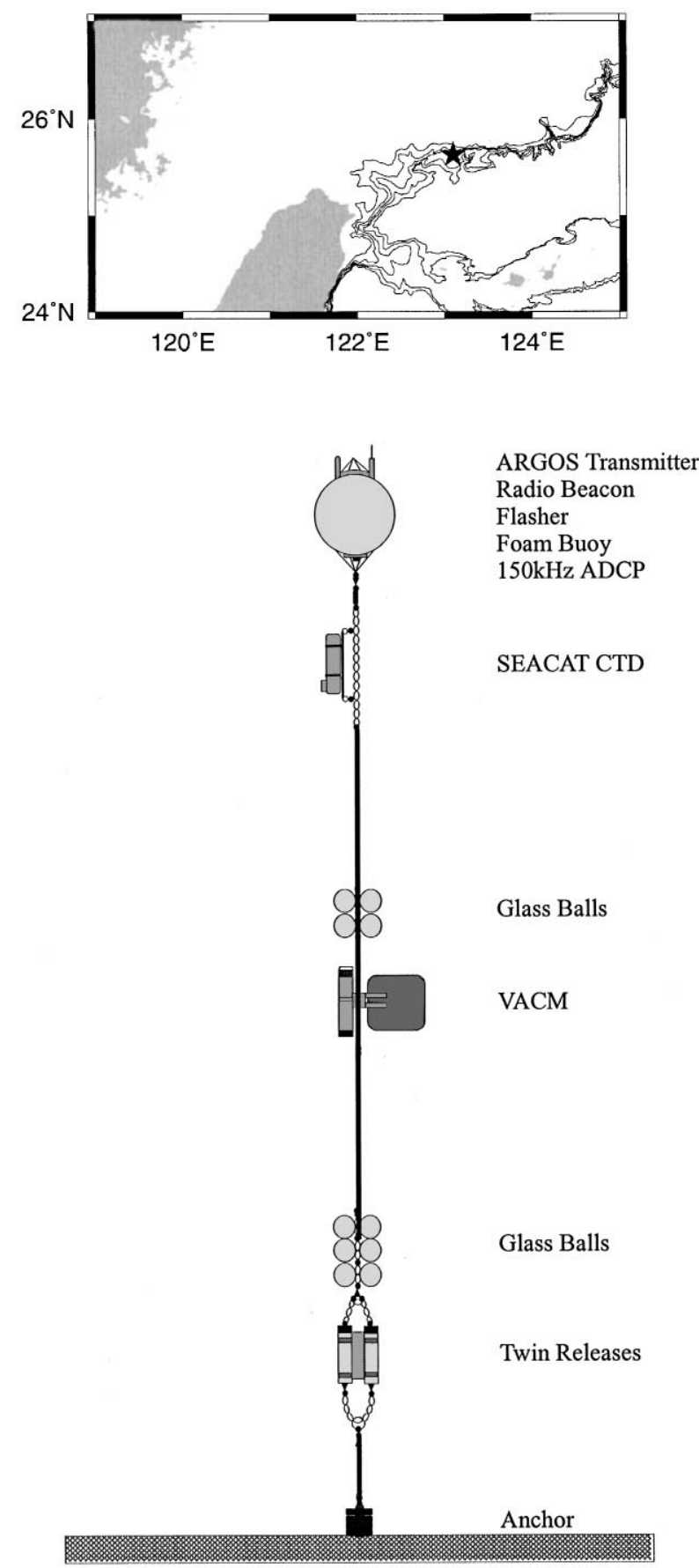

Fig. 2. Location and diagram of ADCP mooring. The upper panel shows the mooring location (asterisk mark) and surrounding bathymetry with depth contours (200-1000 m) at $200 \mathrm{~m}$ intervals. Schematics of the ADCP mooring can be found in the lower panel. 

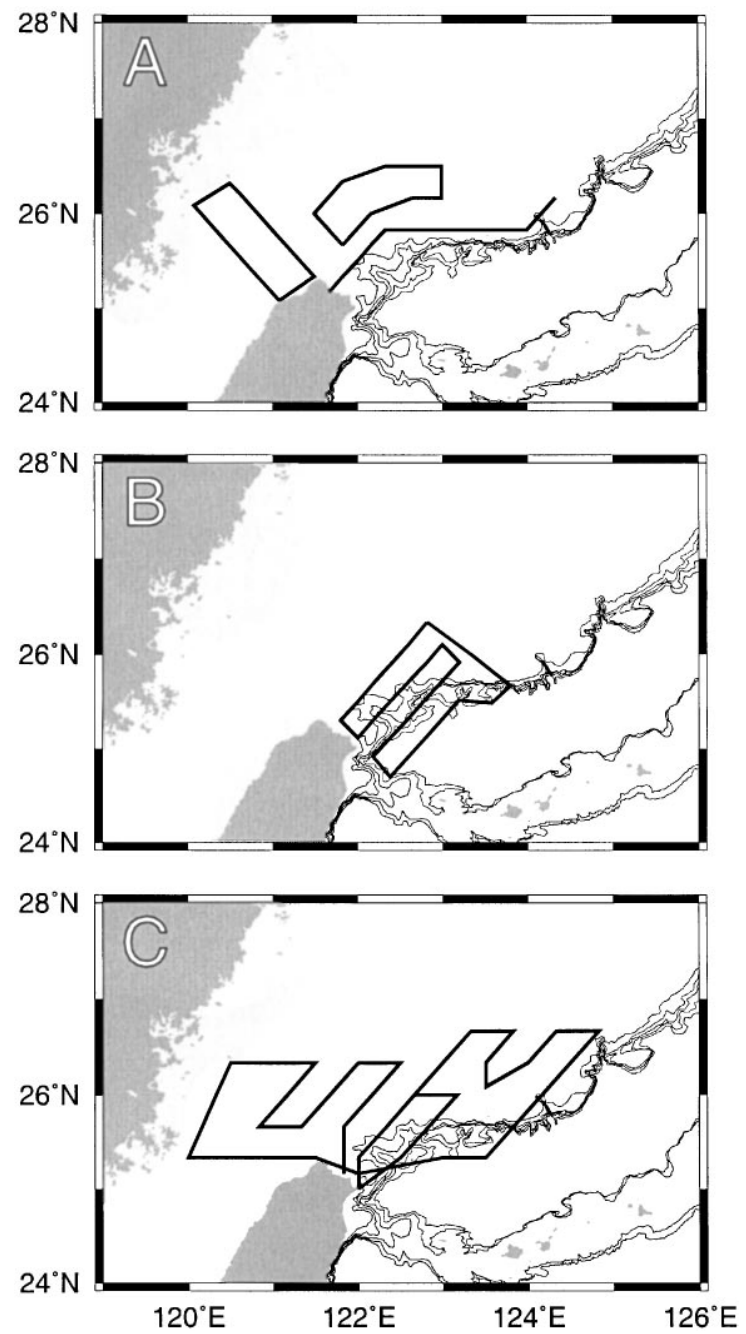

Fig. 3. Three executed cruise tracks: Cruise A (upper panel) from July 24 to August 5, 1996, Cruise B (middle panel) from March 16 to March 18, 1995, and Cruise C (lower panel) from March 3 to March 13, 1997. Thin lines indicate bathymetric contours (200-1000 m deep) at $200 \mathrm{~m}$ intervals.

\section{Analyses and results}

\subsection{Construction of the Kuroshio}

Vertical contours of the Kuroshio current velocity (Fig. 4) before disruption of the shelf break northeast of Taiwan are shown as functions of depth and longitude. This vertical zonal section is centered at $25.125^{\circ} \mathrm{N}$ with a meridional width of $0.25^{\circ}$. The 


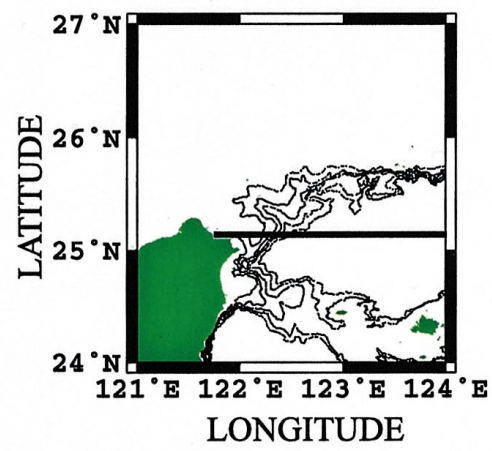

SUMMER
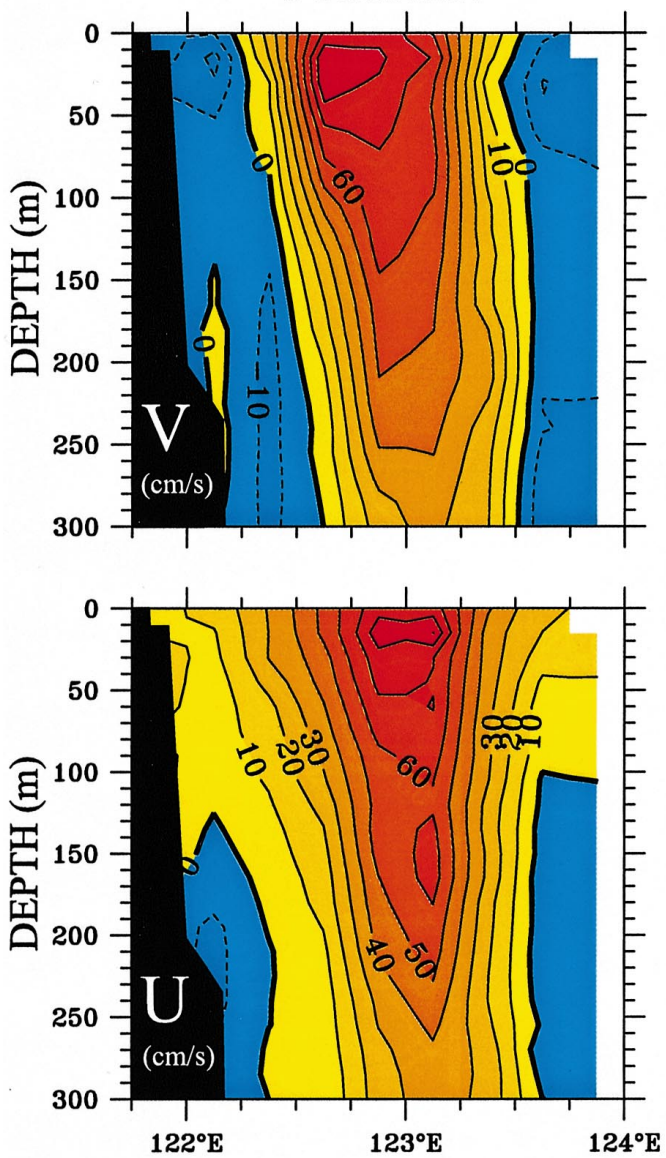

LONGITUDE
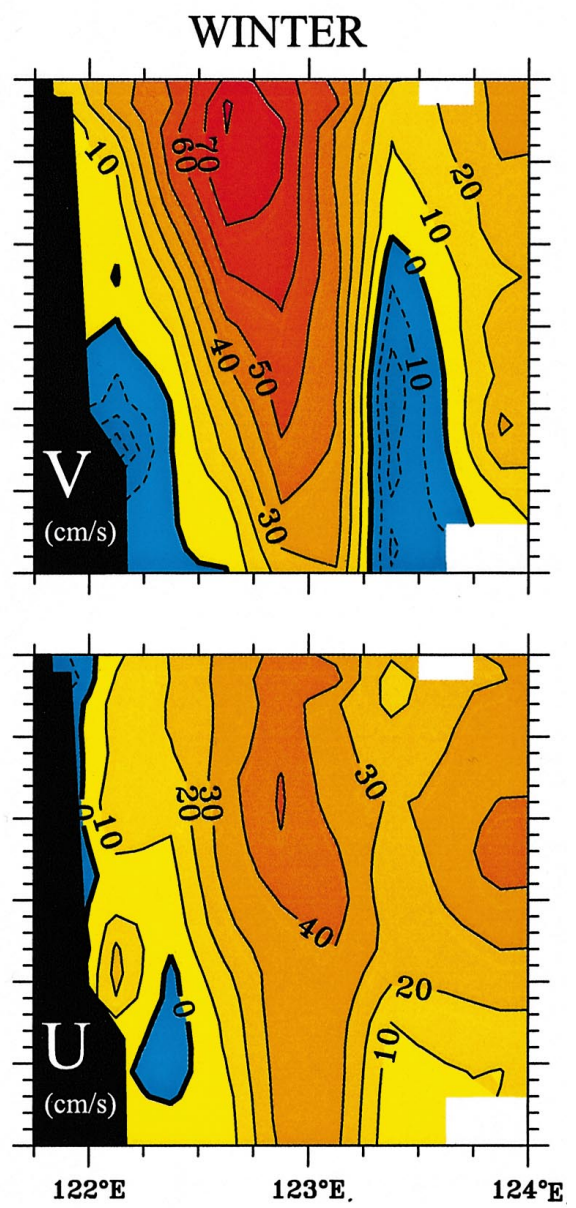

LONGITUDE

Fig. 4. Current velocity distributions as functions of depth and longitude at $25.125^{\circ} \mathrm{N}$. Meridional velocity $(V)$ and zonal velocity $(U)$ in summer and winter can be found in the left and right two panels, respectively, with contour intervals of $10 \mathrm{~cm} \mathrm{~s}^{-1}$. Bold lines indicate values of zero and dashed lines indicate negative values. 
right two panels show the distributions of zonal $(U)$ and meridional $(V)$ current velocity in winter; the left two panels show the distributions of $U$ and $V$ in summer. The Kuroshio was well organized when it first left Taiwan, with a maximum speed near the surface and gradually reducing with depth. In summer the Kuroshio current was northeastward with maximum speeds of over $100 \mathrm{~cm} \mathrm{~s}^{-1}$. At around $1.5^{\circ}$ wide, it kept its distance from the shelf. A southeastward current was observed between Taiwan and the Kuroshio, joining the shelf water to the Kuroshio. In winter the Kuroshio shifted shoreward and became more northward. Its width increased and its core speed decreased (less than $100 \mathrm{~cm} \mathrm{~s}^{-1}$ ). The core of the Kuroshio was also seen to shift slightly, with its western boundary extending onto the shelf. The zonal gradient of $V$ on the western side of the Kuroshio was reduced. No southward current velocity in the upper $150 \mathrm{~m}$ was found between Taiwan and the Kuroshio.

Temperature $(T)$ and salinity $(S)$ distributions along the same vertical-zonal section are shown in Fig. 5. The data was obtained from 849 historical (1985-1997) CTD casts from the ODB/NCOR. In summer a strong temperature front was found around $0.5^{\circ}$ east of Taiwan, roughly coinciding with the front of $V$ indicating the western boundary of the Kuroshio. The isothermal depths (e.g. $20^{\circ} \mathrm{C}$ ) in the upper $200 \mathrm{~m}$ increased rapidly east of the front, becoming flat east of $123.5^{\circ} \mathrm{E}$ at the approximate eastern boundary of the Kuroshio. The value of $S$ generally increased eastward, its minimum found at the surface over the shelf. The shelf water flowed out and spread over a wide region in the upper ocean. The maximum value of $S$ was found at $150 \mathrm{~m}$. In winter the $20^{\circ} \mathrm{C}$ isothermal depth increased just off the shelf and reached its maximum depth around $123.25^{\circ} \mathrm{E}$, indicating that the Kuroshio moved close to the shelf in winter. Water with low salinity was generally confined to the region close to the shelf. The isohaline depths (e.g. $34.7 \mathrm{psu}$ ) also indicate that the core of the Kuroshio moved close to the shelf in winter. In general, distributions of $T$ and $V$ coincided with the thermal wind relation.

As in Fig. 4, Fig. 6 shows current velocity vertical-zonal distributions centered around $25.625^{\circ} \mathrm{N}$. The Kuroshio was disrupted as it collided with the zonally running shelf break, where its construction became more complex. In general, the Kuroshio moved eastward at reduced speeds. $V$ was weak and mainly confined to the upper $100 \mathrm{~m}$. Differences in current distributions for the two seasons were significant: in summer the core of the Kuroshio (eastward current velocity) was submerged to a depth of $200 \mathrm{~m}$, with a maximum speed of around $70 \mathrm{~cm} \mathrm{~s}^{-1}$. On the shelf west of the Kuroshio, the westward current spanned nearly the entire water column. A large northward current with a maximum speed of $30 \mathrm{~cm} \mathrm{~s}^{-1}$ in the upper oceanic regions was found between the westward current and the core of the Kuroshio, indicating that most of the subsurface Kuroshio current was redirected eastward due to the stiff zonally running shelf break. The surface Kuroshio, however, proceeded over the shelf break and intruded onto the southern shelf of ECS, separating into the branch current to the north and the mainstream to the east. Around $122.25-123.0^{\circ} \mathrm{E}$ (near the head of NMHC), the southwestward current dominated the water column at depths lower than $50 \mathrm{~m}$. This was the upstream of the counterclockwise circulation that carried the subsurface Kuroshio water onto the shelf northeast of Taiwan (Tang et al., 1999). The current on the shelf was generally northwestward. In winter the Kuroshio was still 

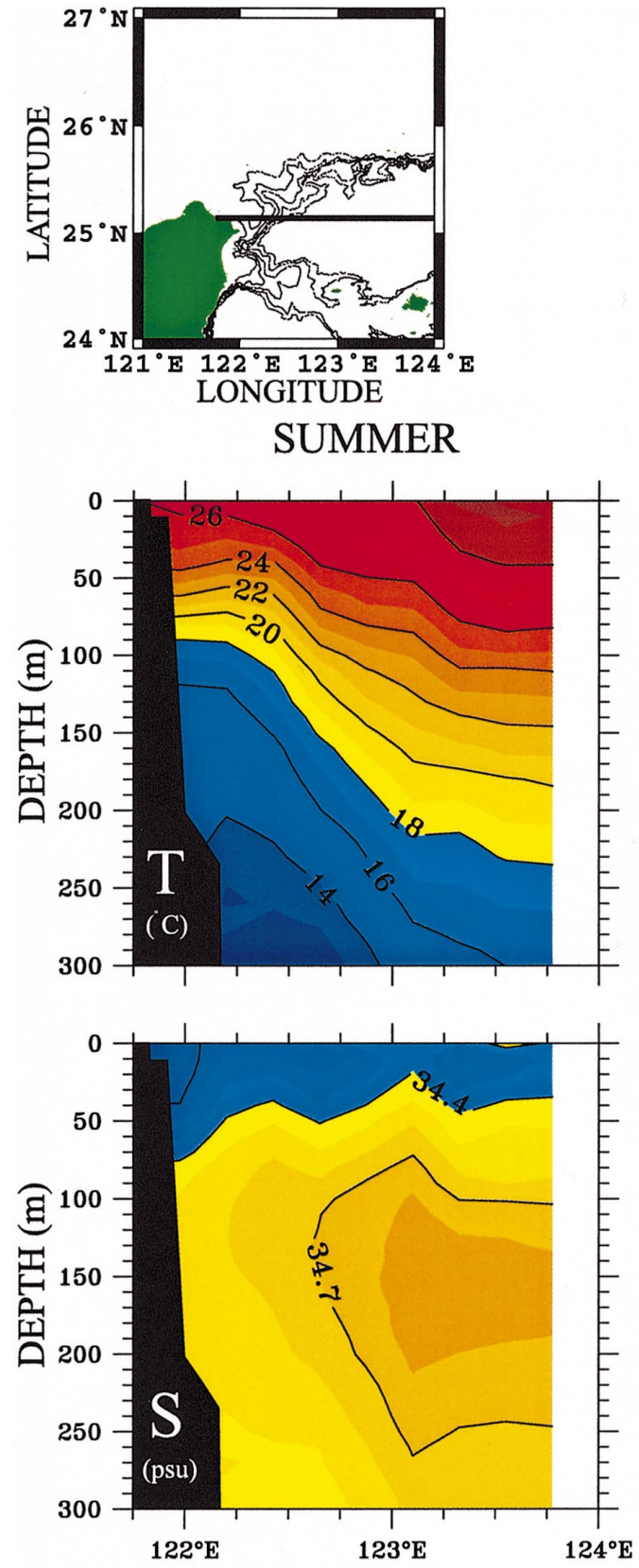

LONGITUDE
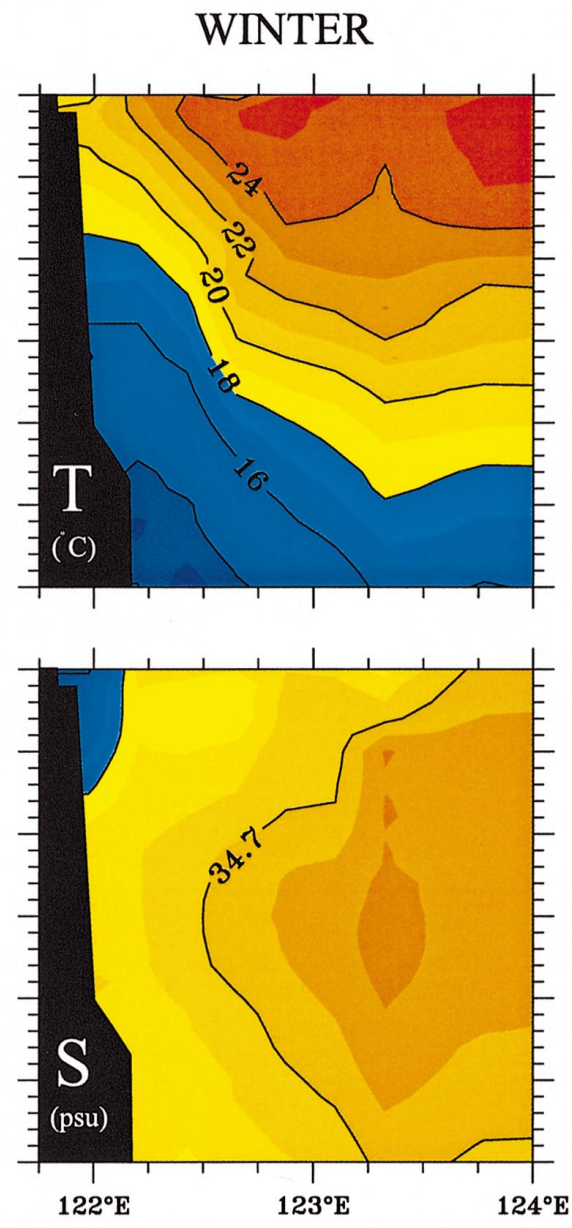

LONGITUDE

Fig. 5. Temperature and salinity distribution as functions of depth and longitude at $25.125^{\circ} \mathrm{N}$. Temperature $(T)$ and salinity $(S)$ in summer and winter are shown in the left and right two panels, respectively. The contour interval is $2^{\circ} \mathrm{C}$ for $T$ and 0.3 psu for $S$. 


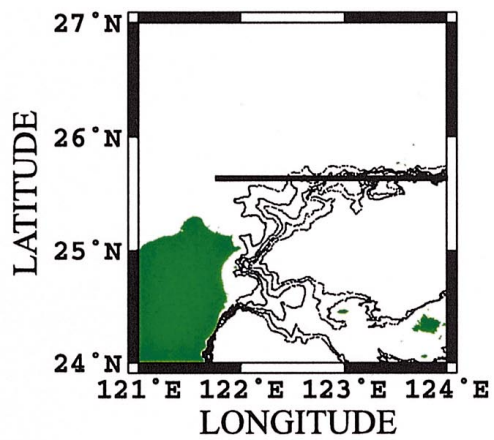

SUMMER
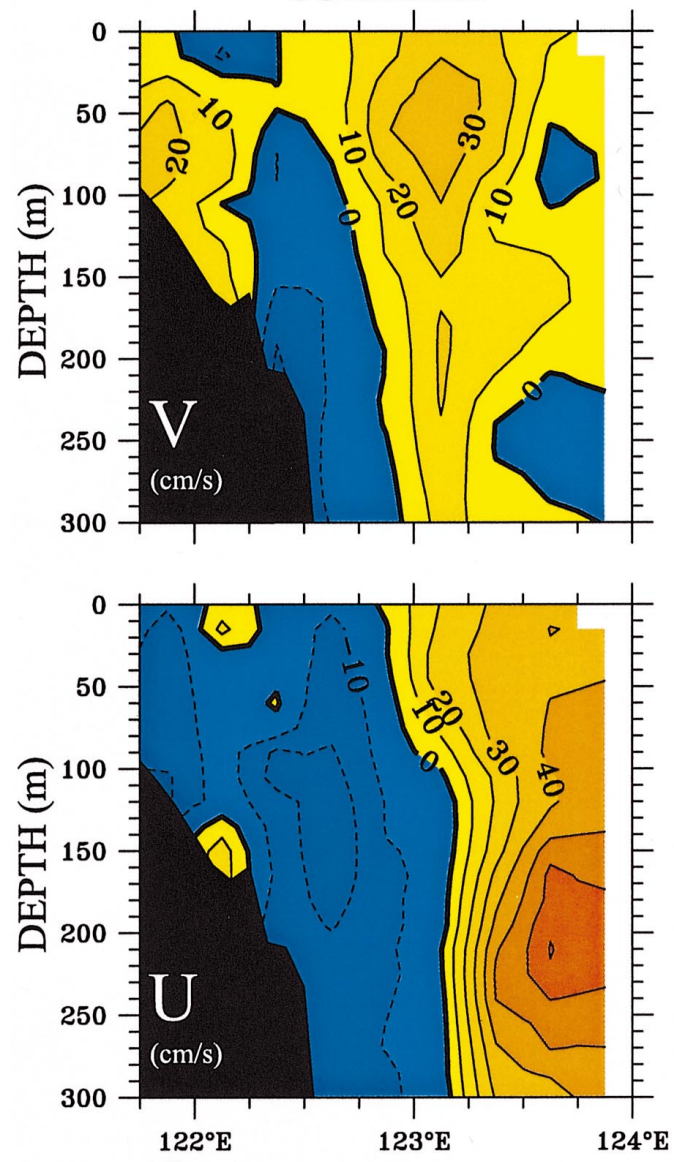

LONGITUDE
WINTER
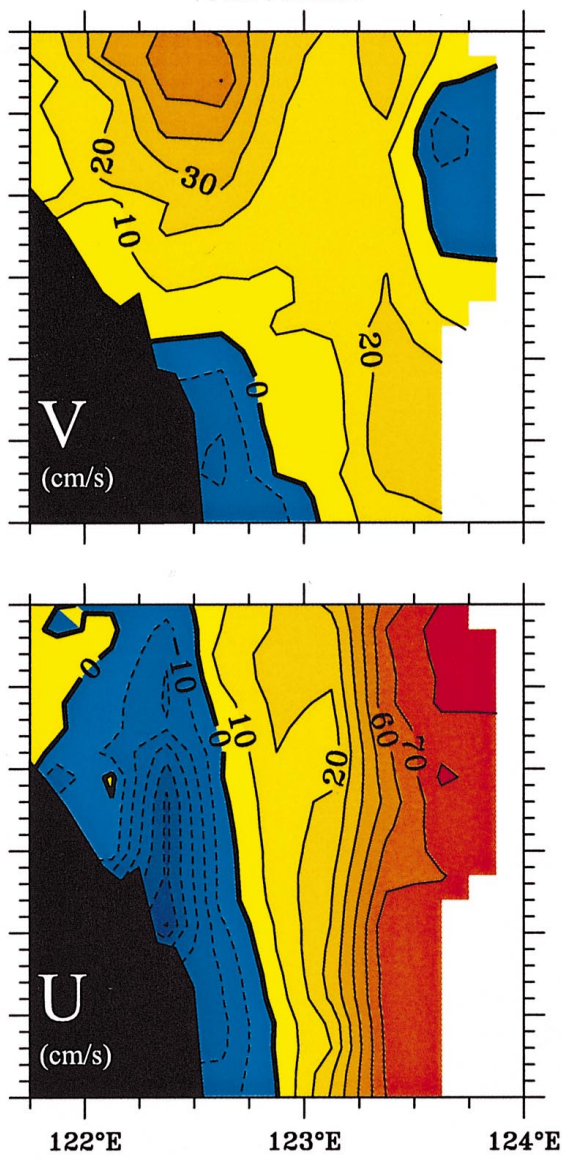

LONGITUDE

Fig. 6. Same as Fig. 4 except at $25.625^{\circ}$ N. 
eastward but its speed increased and its core rose close to the surface. The domain of eastward flow expanded to the west, while the region of westward flow was smaller but had greater speed. The core of the northward current in the upper ocean was much more westward and had greater speed. This westward shift could be related to the seasonal migration of the Kuroshio (see below). Again, the separation of eastward and northward current velocity cores reflects the separation of the Kuroshio into the northward core of the branch current and the eastward core of the mainstream. As in the findings of Tang and Yang (1993), the southwestward current was only seen below $200 \mathrm{~m}$ at the edge of the shelf.

Distributions of $T$ and $S$, obtained from 708 CTD casts along the same section, are shown in Fig. 7. In summer a region of cold water, visible in the infrared images, was found at the head of NMHC, east of which the isothermal depths increased to around $123.5^{\circ} \mathrm{E}$. Unlike in previous regions, the distribution of $T$ and $V$ in this section does not correspond to the thermal wind relation, possibly due to the impact of bottom topography, which might have ruptured the thermal wind relation, or that of the ageostrophic flow. The value of $S$ also increased eastward with a maximum of around $200 \mathrm{~m}$. The region of low $S(<34.4 \mathrm{psu})$ was wide but confined to the upper ocean $(<50 \mathrm{~m})$. The value of $S$ was greater in the region of cold water than in surrounding areas, indicating an upwelling around the head of NMHC. In winter the value of $T$ increased eastward just off the shelf, reflecting the extension of the Kuroshio onto the shelf. The upwelling at NMHC was visible but confined to the lower water column. The region of low $S$, confined to the upper ocean, shrunk westward, while the region of high $S(>34.7 \mathrm{psu})$ shifted shoreward, indicating the shoreward migration of the Kuroshio.

Fig. 8 shows the current velocity north of Taiwan at a depth of $20 \mathrm{~m}$. The seasonal migration of the Kuroshio occurred northeast of Taiwan. In summer the Kuroshio moved seaward with a region of weak (or even no) flow on the northern shelf of Taiwan. The northeastward Kuroshio and northwestward Taiwan Strait outflow were found on the western and eastern sides of the region, respectively. The absence of counterclockwise motion, visible in the snapshot current observation (Tang et al., 1999), will be discussed later. In winter the Kuroshio moved shoreward, with the region of weak flow only visible on the northern tip of Taiwan, where the Taiwan Strait outflow combined with the Kuroshio.

\subsection{Kuroshio migration}

Vertical distributions of the composite current velocity northeast of Taiwan are shown as a function of depth and time (see Fig. 9). The data has been $36 \mathrm{~h}$ low-pass filtered to eliminate any high-frequency fluctuations dominated by the $M_{2}$ tidal current velocity. The upper and lower panels display the $U$ and $V$, respectively. The current of $U$ for the upper $100 \mathrm{~m}$ was eastward with few exceptions. The maximum value of the eastward current velocity was $50 \mathrm{~cm} \mathrm{~s}^{-1}$ near the surface, decreasing with greater depth. The eastward current was usually faster in summer than in winter, though definite patterns in seasonal variation were not evident. The intra-seasonal variation of $U$ in the upper $100 \mathrm{~m}$ was visible, however, with intra-seasonal variations 


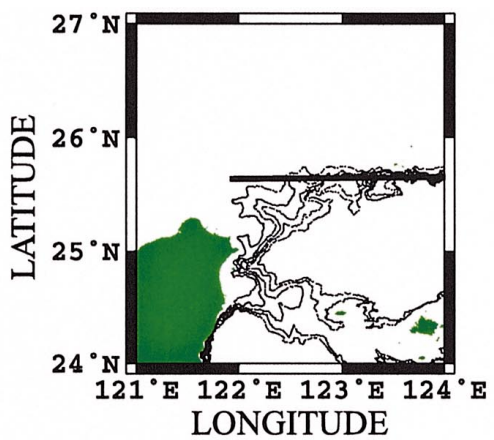

SUMMER

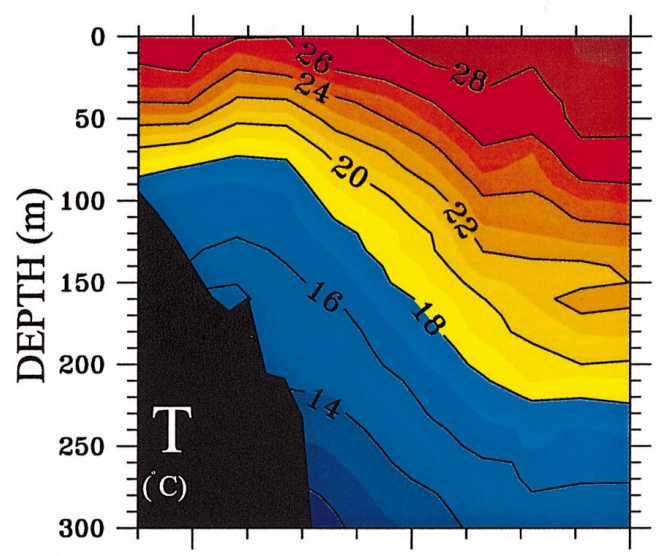

WINTER
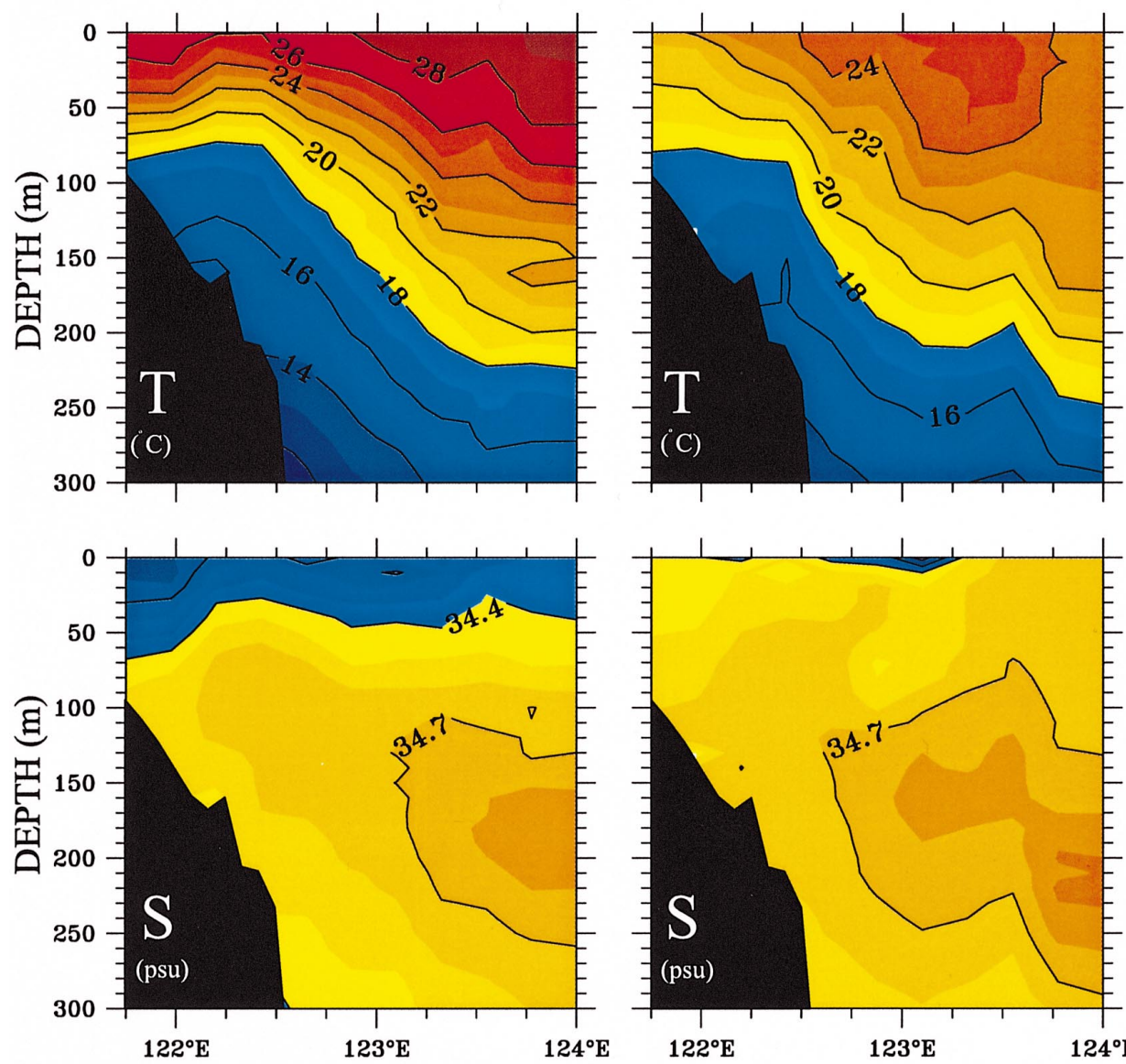

LONGITUDE

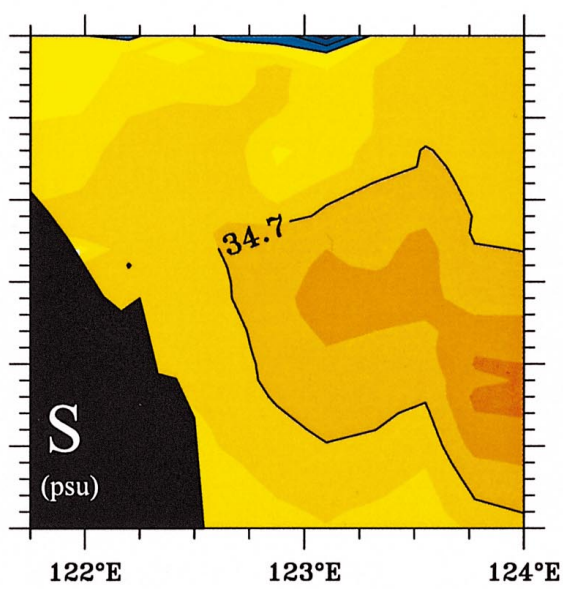

LONGITUDE

Fig. 7. Same as Fig. 5 except at $25.625^{\circ} \mathrm{N}$. 


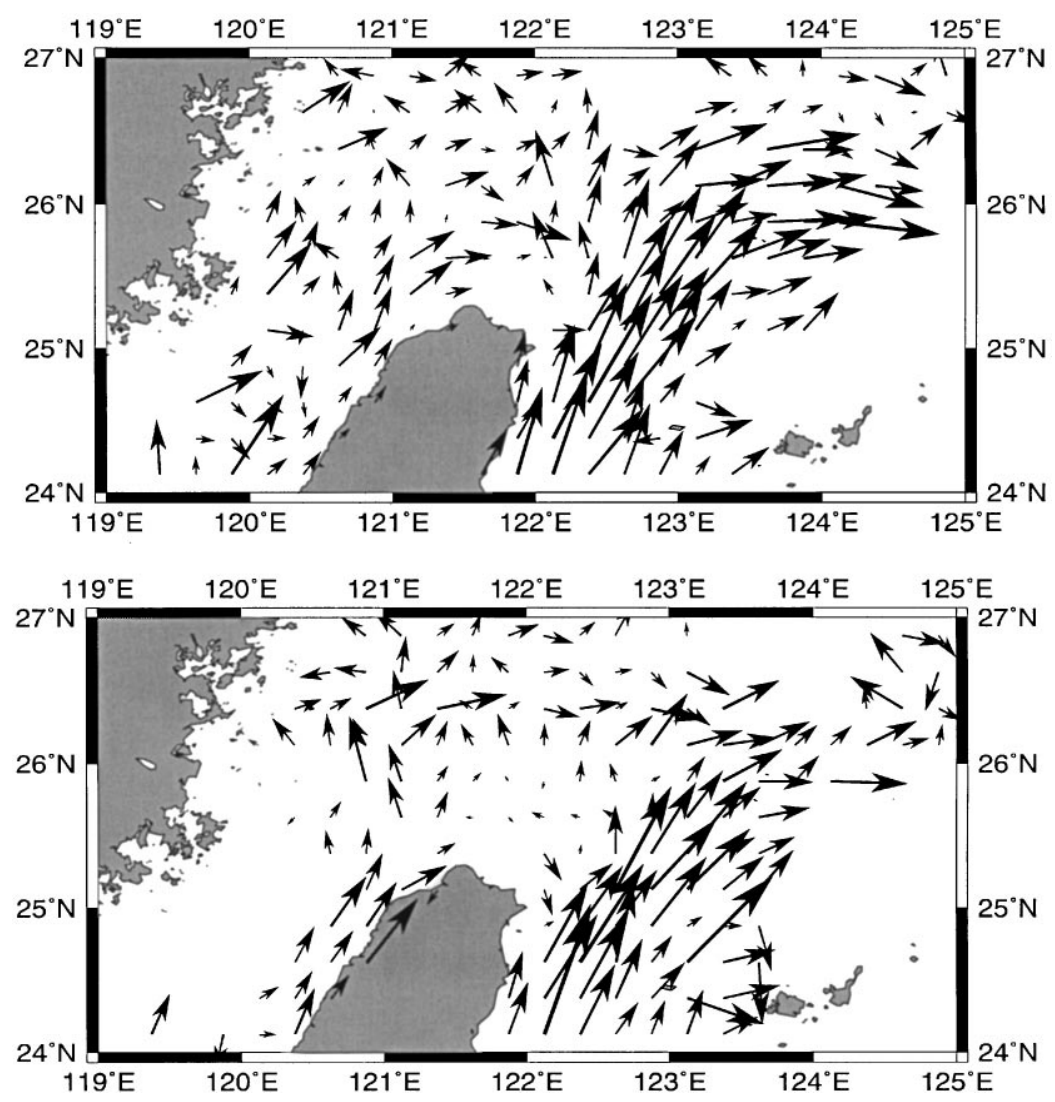

Fig. 8. Composite Sb-ADCP current velocity vectors at $20 \mathrm{~m}$ depths. The upper panel represents summer, the lower panel winter.

from a few days to a month. No significant fluctuation at any specific frequency band was found in the variance spectrum (not shown). Below $100 \mathrm{~m}$, the $U$ displayed significant seasonal variation, with eastward (in winter) and westward (in summer) flows alternating. Seasonal transitions occurred around April and October. The westward current in summer was generally seen below $100 \mathrm{~m}$, though it sometimes surfaced or submerged below $150 \mathrm{~m}$. Current velocity recorded by the VACM current meter indicates that the westward current could extend to over $340 \mathrm{~m}$ at a recorded maximum speed of over $60 \mathrm{~cm} \mathrm{~s}^{-1}$. In winter the $U$ below $100 \mathrm{~m}$ was generally dominated by the weak eastward current. The occasional appearance of the westward current, especially in December, indicates that intra-seasonal variation can be as great as seasonal variation. Again, the range of intra-seasonal variation stretched from several days to a month.

The $V$ (shown in lower panel) was northward and mainly confined to the upper water column. Almost no southward flow was seen over the entire record. Both seasonal and intra-seasonal variations of $V$ were found. In general, the velocity of 


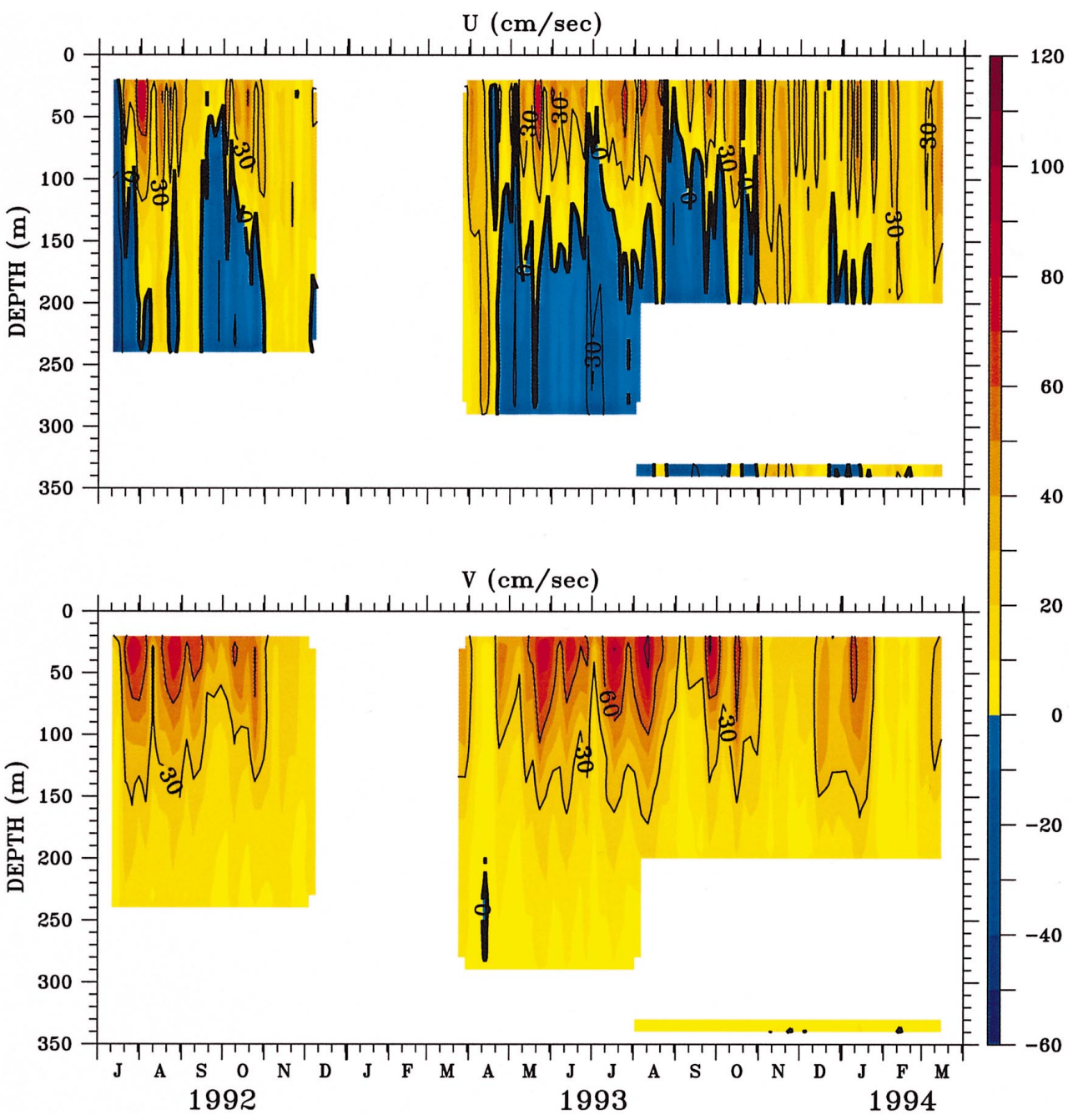

Fig. 9. Current velocity distributions as functions of depth and time. $U$ and $V$ are represented in the upper and lower panels, respectively, with contour intervals of $30 \mathrm{~cm} \mathrm{~s}^{-1}$. Bold lines indicate values of zero. All data has been $36 \mathrm{~h}$ low-pass filtered.

$V$ was greater in summer than in winter, but rapid northward flow was also occasionally seen in winter (e.g. January 1994). Intra-seasonal variation was relatively negligible.

Displaying the relationship between water temperature, salinity, and current velocity, the time series of $T$ and $S$ recorded by the moored SEACAT CTD and the value of $U$ at $190 \mathrm{~m}$ are shown in Fig. 10. Since the SEACAT CTD was deployed at three different depths (from $215 \mathrm{~m}$ to $275 \mathrm{~m}$ ), no useful comparison between the three deployments can be made. The conductivity sensor failed in the second deployment 

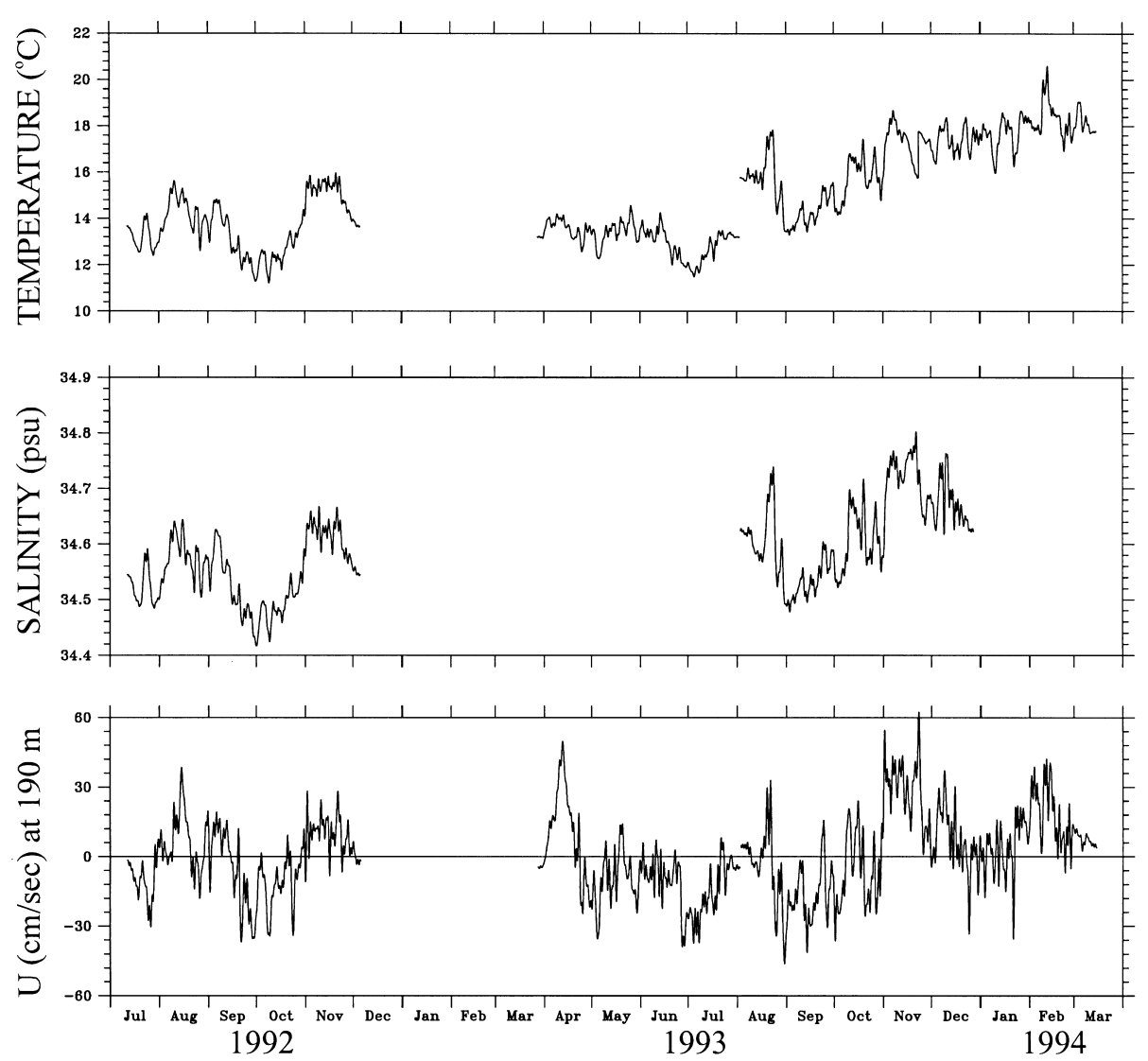

Fig. 10. Time series of (a) $T$, (b) $S$, and (c) $U$ at $190 \mathrm{~m}$ depths. All data has been $36 \mathrm{~h}$ low-pass filtered.

and in part in the third. All the data were $36 \mathrm{~h}$, low-pass filtered to remove high-frequency fluctuations. Both seasonal variations and intra-seasonal variations for water temperature and salinity were evident, the water being warmer and more saline in winter than in summer. Peak-to-peak comparisons between $T, S$, and $U$ at $190 \mathrm{~m}$ showed that $T$ not only varied in phase with $S$, but also varied nearly in phase with $U$ at $190 \mathrm{~m}$, with very few exceptions (e.g. $U$ decelerated while $T$ retained its value in December 1993). The coherence between $T$ and $S$ and between $T$ and $U$ at $190 \mathrm{~m}$ are shown in Fig. 11, in which the upper two panels represent the coherence squared and phase between $T$ and $S$ for the first and third deployments, and the lower two panels are the coherence squared and phase between $T$ and $U$ at $190 \mathrm{~m}$ for the first and third deployments. Coherence was generally high and nearly in-phase in the low-frequency portion. The similar measurements of $T, S$, and $U$ at nearly the same depth, as well as their simultaneous variation at the mooring site, could be related to the migration of the Kuroshio.

Similar to the current velocity and $T$ and $S$ distributions shown in Figs. 6 and 7, the $U$ at the mooring site was eastward in the upper water column and westward in the 

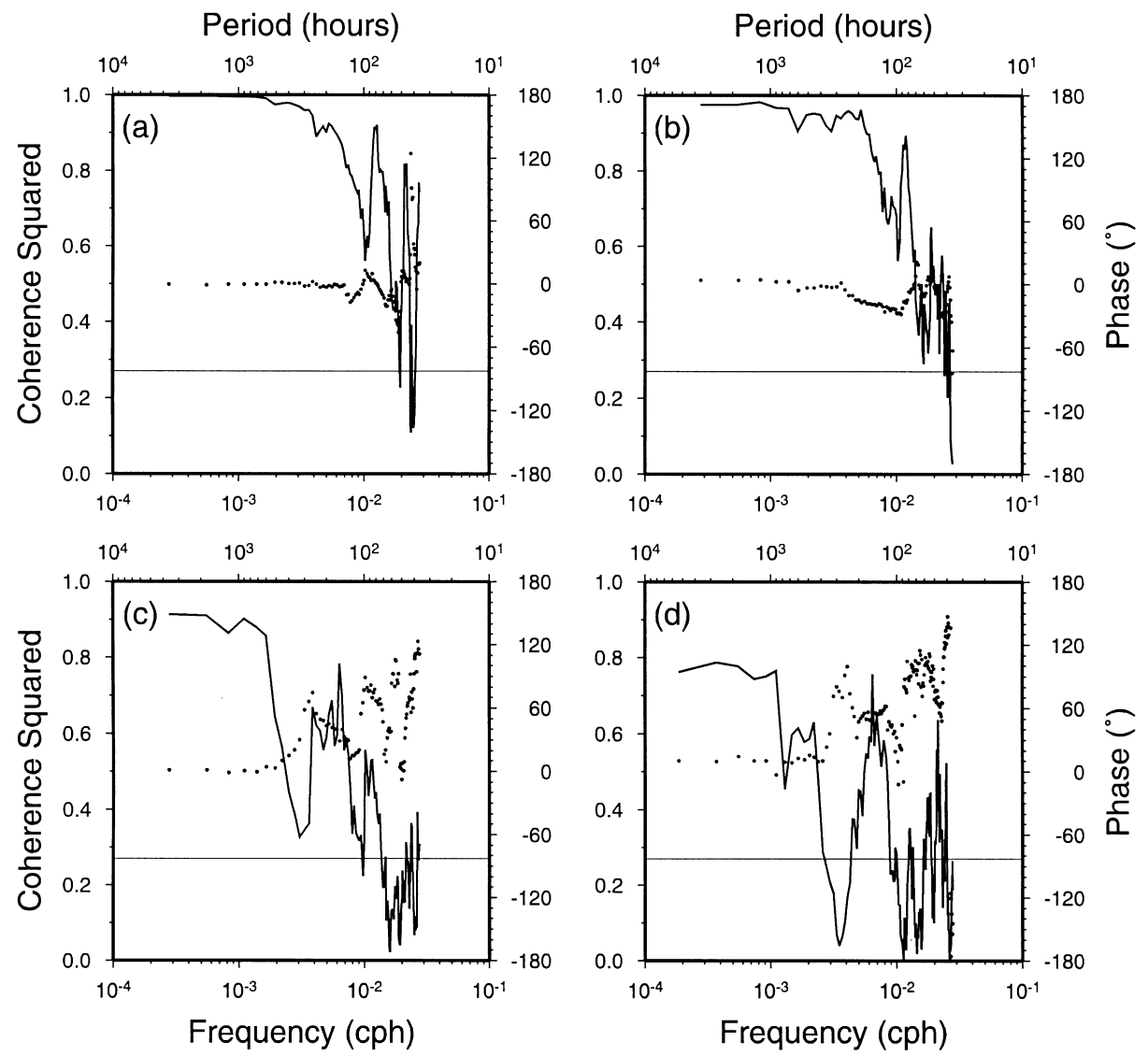

Fig. 11. The coherence squared and phase between $T$ and $S$ and $T$ and $U$ at $190 \mathrm{~m}$ depths. Panels (a) and (b) represent the coherence squared and phase between $T$ and $S$ for the first and third deployments, respectively; Panels (c) and (d) represent the coherence squared and phase between $T$ and $U$ for the first and third deployments. Solid lines indicate the coherence squared and dotted lines indicate phase. The thin line marks the $90 \%$ confidence interval.

lower water column during summer, and eastward over the entire water column during winter. The zero-crossing line of $U$ ran from upper-west to lower-east. Both $T$ and $S$ were lower in summer than in winter, their contours also running from upper-west to lower-east. The westward (shoreward) progression of the Kuroshio may have caused the simultaneous increase in $T$ and $S$ and the acceleration of $U$ (or the decrease of westward current velocity) in the lower water column at the mooring site.

\subsection{Mesoscale flow pattern north of Taiwan}

Fig. 12 contains the seasonal mesoscale flow patterns north of Taiwan, obtained from four snapshot observations of current velocity at $16 \mathrm{~m}$ as well as various infrared 


\section{SUMMER}

(I)

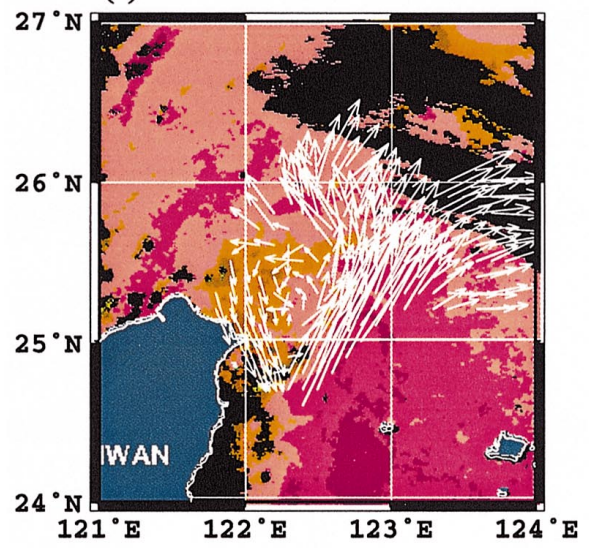

(II)

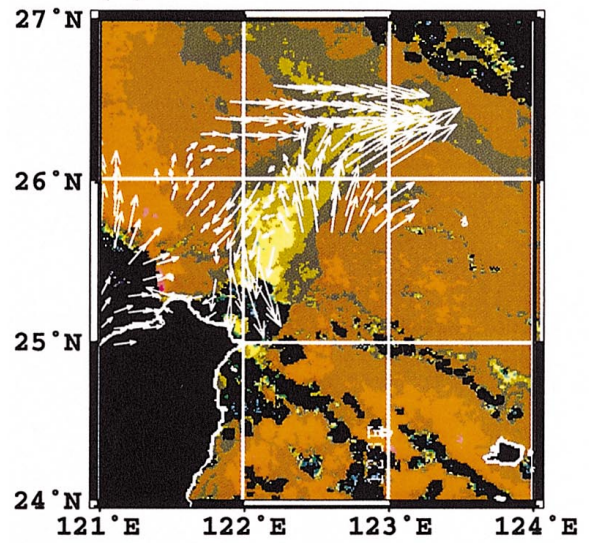

WINTER

(III)

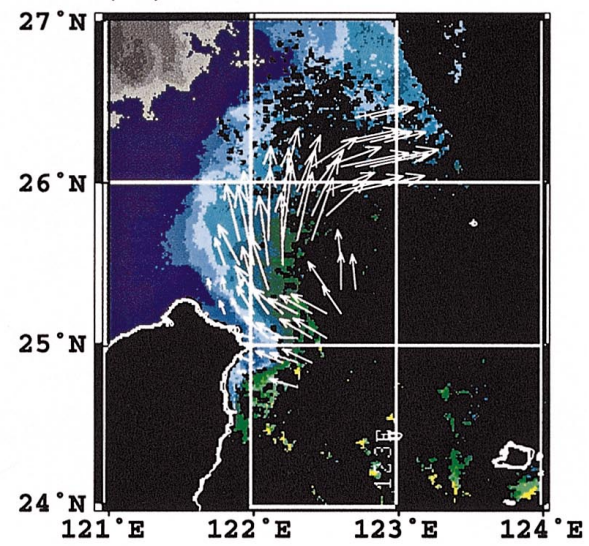

(IV)

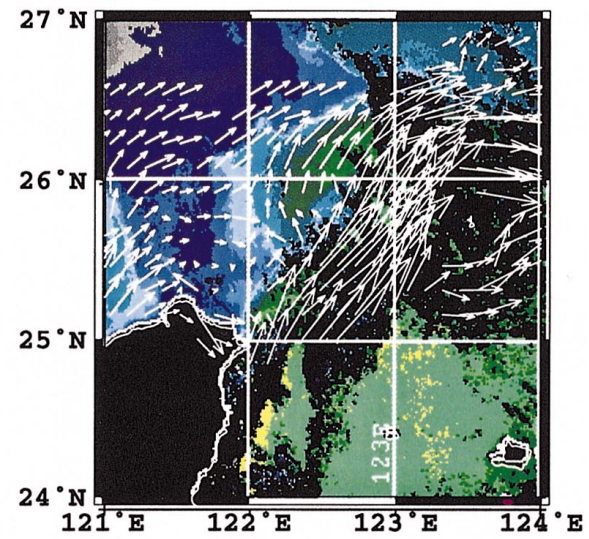

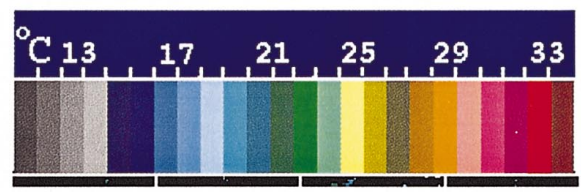

Fig. 12. Current velocity vectors from four snapshot Sb-ADCP observations at $16 \mathrm{~m}$ depths. Panel I displays the results of Tang et al. (1999); Panels II, III, and IV display data obtained from Cruises A, B, and C. Panels I and II represent summer; Panels III and IV represent winter. Overlaid infrared images of sea surface temperature were obtained from (a) NOAA-11 on August 12, 1994 (Panel I), (b) NOAA-12 on August 5, 1996 (Panel II), (c) NOAA-12 on March 3, 1995 (Panel III), and (d) NOAA-12 on March 5, 1997 (Panel IV). 
images, both taken at the same time. The results of Tang et al. (1999) (labeled I) are shown in Panel I, while the other three panels (labeled II-IV) display the results obtained from Cruise A, B, and C. Panels I and II were taken in summer and Panels III and IV in winter. Although the survey regions are different, the two mesoscale patterns in summer match quite well. It can be seen that the Kuroshio main stream was redirected toward the east, with a branch current forming around NMHC. Southwest of this branch current, a counterclockwise circulation revolved around the MHC, consisting of a southwestward Kuroshio countercurrent on the shelf and a seaward flow at the northern tip of Taiwan. There were small discrepancies between these two summer flow patterns: it was found that the branch current in Panel II shifted slightly westward and the counterclockwise circulation shifted slightly northwestward; the speed of the counterclockwise circulation was also greater in Panel II than in Panel I. The new current velocity observation (Panel II) not only provided supporting evidence for the findings of Tang et al. (1999), but also the chance to examine the Taiwan Strait outflow. As in the Strait itself, the Taiwan Strait outflow generally flowed northeastward as it left the Strait. The presence of counterclockwise circulation blocked the Taiwan Strait outflow to the east and kept it flowing northward, a section of the outflow eventually joining with the branch north of the counterclockwise circulation.

As in the flow patterns, the similarities between the two infrared summer images (Panels I and II) are offset by a few notable differences. Both of them show cold water northeast of Taiwan. The cold water in Panel II formed a belt along the shelf break, extending from the coast of Taiwan to the shelf of ECS. This area was shortened in Panel I, in which no cold water could be found north of NMHC. The location of the cold water near Taiwan nearly coincided with that of the counterclockwise circulation: it was more eastern in Panel II than in Panel I, indicating the eastward shift of the counterclockwise circulation as well as that of the Kuroshio. This result corresponds with the previous findings. The cold water on the shelf of ECS could be related to the movement of the branch current. With the intrusion of this current onto the shelf of ECS, the subsurface water could have been upwelled due to the shallow topography.

The two mesoscale flow patterns in winter were different from each other as well as from the flow patterns in summer. Seasonal differences were more pronounced than intra-seasonal differences. During the on-shelf intrusion in winter, the Kuroshio was much closer to the shore than in summer. The counterclockwise circulation nearly disappeared, and the Taiwan Strait outflow joined with the branch current after it left the Strait. Panel III shows the on-shelf intrusion of the Kuroshio just offshore of the northern tip of Taiwan. Panel IV shows it to be further north. The flow pattern in winter revealed an interesting feature: the current over the entire northern shelf of Taiwan flowed mainly northward against the winter monsoon.

Fig. 13 contains four snapshot flow patterns at $80 \mathrm{~m}$. Since the measurements made in Cruises A-C were mainly confined to the shelf region, the amount of data below this depth was significantly less. The overall characteristics at $80 \mathrm{~m}$ were similar to those at $16 \mathrm{~m}$, differing only in the second summer measurement in which the branch current extended to the west and the counterclockwise circulation became obscured. 

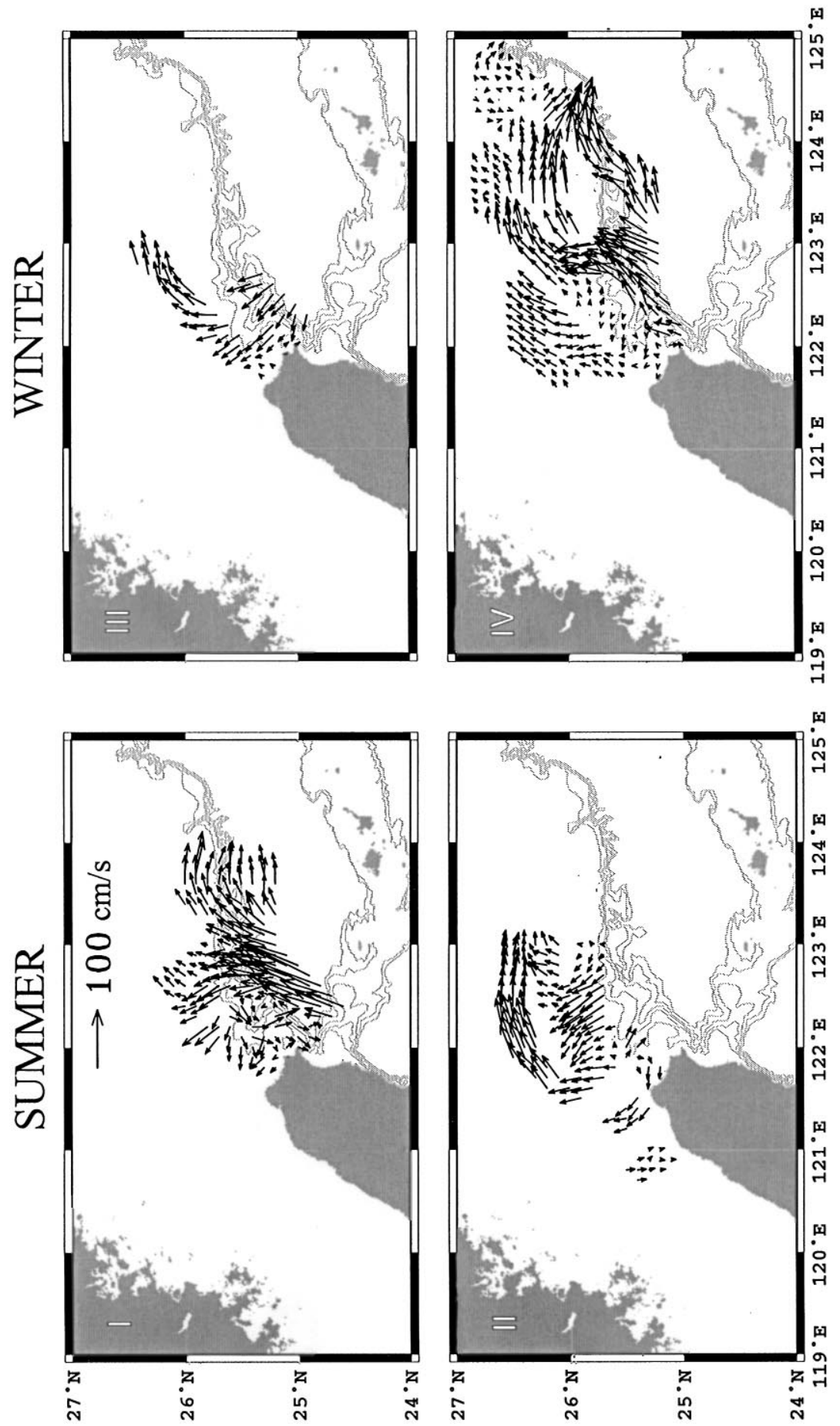
This may be attributed to a lack of measurements in the deep-water region. However, the summer flow pattern at $80 \mathrm{~m}$ was useful in that it clearly showed the interaction of the Taiwan Strait outflow and the counterclockwise circulation. The southwestward countercurrent, a part of the counterclockwise circulation, was split as it encountered the coast of Taiwan, its eastern branch flowing off the shelf of the northern tip of Taiwan, its western branch flowing northwestward off the northern coast of Taiwan. The western branch changed the course of the Taiwan Strait outflow toward a more westerly direction. The Taiwan Strait outflow in summer was therefore prohibited from direct interaction with the Kuroshio.

\section{Discussion and conclusions}

Various conclusions can be made based upon the above discussion. The migration of the Kuroshio could be mainly responsible for the low-frequency variations of observed $T, S$, and $U$ values at the mooring site. As such, observed $T, S$, and $U$ values could be used as indicators for the migration of the Kuroshio. Although variations in $V$ as the Kuroshio proceeded westward were more pronounced than those of $U$, the moored $V$ might not be the best indicator since its core (Fig. 6) was located east of the mooring site. Both winter infrared images showed the presence of a sharp temperature front on the northern shelf of Taiwan formed by the interaction of the warm Kuroshio water with the cold shelf water. The close correspondence of the temperature front with the horizontal velocity front also makes it a good indicator for the on-shelf intrusion of the Kuroshio.

With respect to seasonal and intra-seasonal variations, the absence of counterclockwise circulation in the composite flow pattern (Fig. 8) in summer could be related to its own intra-seasonal migration. In addition to the snapshot current observations shown above, there have been others which, although incomplete or limited in scale, all indicate the intra-seasonal migration of the counterclockwise circulation. As the counterclockwise circulation moved seaward, the northeastward Taiwan Strait outflow prevailed on the northern shelf of Taiwan; as it moved shoreward, the southwestward countercurrent prevailed. The opposing currents of the Taiwan Strait outflow and the countercurrent alternately dominated the region, and the resulting area of weak flow in the composite current velocity field north of Taiwan can be attributed to their mutual cancellation.

Tang and Yang (1993) found that the southwestward countercurrent was consistently shown in the lower $(>150 \mathrm{~m})$ water column, even in winter. Their data also reflected the weakness of the countercurrent velocity in winter relative to summer. The results of the present study generally correspond with their findings, with various

Fig. 13. Current velocity vectors from four snapshot Sb-ADCP observations at $80 \mathrm{~m}$ depths. Panel I shows the results of Tang et al. (1999); Panels II, III, and IV display data obtained from Cruises A, B, and C. Panels I and II represent summer; Panels III and IV represent winter. Thin lines indicate bathymetric contours (200-1000 $\mathrm{m}$ deep) at $200 \mathrm{~m}$ intervals. 
exceptions: snapshot observations in winter showed that the countercurrent in the lower water column was evident in the data (not shown) obtained from Cruise B, but was negligible in the data (not shown) from Cruise C. It is possible that the countercurrent weakens or even vanishes in winter.

The correspondence between moored current velocities and island winds at Peng Chia $\mathrm{Yu}$ (approximately $100 \mathrm{~km}$ southwest of the mooring site) is low, indicating that local wind had little impact on the Kuroshio. Hsueh (personal communication, 1999) found in his numerical study that the migration of the Kuroshio northeast of Taiwan was caused by a northward propagating eddy which formed northwest of the Luzon Strait. Lacking annual variation, the results of his model do not correspond well with the present and previous (Chuang et al., 1993; Tang and Yang, 1993) moored current velocities observed northeast of Taiwan, which clearly delineate seasonal variation.

The present study only provides a qualitative description of the migration of the Kuroshio and the mesoscale flow pattern north of Taiwan. Further study is required to fully investigate the complex dynamics of the region's migrational variation.

\section{Acknowledgements}

This work was supported by the National Science Council of the Republic of China under grants NSC 85-2611-M-002A-019-K2 and NSC 85-2611-M-019-014-K2. We would like to express our heartfelt thanks to the Taiwan Fisheries Research Institute for providing the infrared images, and the Ocean Data Bank/National Center for Ocean Research, National Science Council, for the historical current velocity and hydrographic data. The assistance of the captains and crew of the $\mathrm{R} / \mathrm{V}$ Ocean Researcher I and II is also gratefully appreciated.

\section{References}

Chern, C.-S., Wang, J., 1989. On the water masses at northern offshore area of Taiwan. Acta Oceanographica Taiwanica 22, 14-32.

Chuang, W.-S., 1986. A note on the driving mechanisms of current in the Taiwan Strait. Journal of Oceanography Society Japan 42, 355-361.

Chuang, W.-S., Li, H.-W., Tang, T.-Y., Wu, C.-K., 1993. Observations of the countercurrent on the inshore side of the Kuroshio northeast of Taiwan. Journal of Oceanography 49, 581-592.

Chuang, W.-S., Liang, W.-D., 1994. Seasonal variability of intrusion of the Kuroshio water across the continental shelf northeast of Taiwan. Journal of Oceanography 50, 531-542.

Fan, K.-L., 1980. On upwelling off northeastern shore of Taiwan. Acta Oceanographica Taiwanica 11, 105-117.

Liu, K.-K, Gong, G.-C., Shyu, C.-Z., Pai, S.-C., Wei, C.-L., Chao, S.-Y., 1992. Response of Kuroshio upwelling to the onset of the northeast monsoon in the sea north of Taiwan: observations and a numerical simulation. Journal of Geophysical Research 97, 12,511-12,526.

Qiu, B., Imasato, N., 1990. A numerical study on the formation of the Kuroshio Counter Current and the Kuroshio Branch Current in the East China Sea. Continental Shelf Research 10, 165-184.

Sun, X., 1987. Analysis of the surface path of the Kuroshio in the East China Sea. In: Sun, X. (Ed.), Essays on the Investigation of Kuroshio. Ocean Press, Beijing, pp. 1-14 (in Chinese with English abstract). 
Tang, T.Y., Ma, J.C., 1995. A note on the accuracy of shipboard ADCP on Ocean Researcher I. Acta Oceanographic Taiwanica 34, 71-81.

Tang, T.Y., Hsueh, Y., Yang, Y.J., Ma, J.C., 1999. Continental slope flow northeast of Taiwan. Journal of Physical Oceanography 29, 1353-1362.

Tang, T.Y., Yang, Y.J., 1993. Low frequency current variability on the shelf break northeast of Taiwan. Journal of Oceanography 49, 193-210.

Uda, M., Kishi, A., 1974. Cyclonic cold eddies along the edge of the Kuroshio current in relation to the genesis and passage of cyclones, I. Waters north of Taiwan. The Kuroshio III. Proceedings of the 3rd Symposium, Bangkok, Thailand, 1972, pp. 199-218.

Wang, J., Chern, C.-S., 1988. On the Kuroshio branch in the Taiwan Strait during wintertime. Progress in Oceanography 21, 469-491. 